\title{
Belief in Science and Attitudes Toward COVID-19: A Demographic Standardization Approach to China-US Comparison, 2020
}

\author{
Yue Qian'; Yongai Jinn ${ }^{2, *} ;$ Yu Xie ${ }^{3,4}$
}

\begin{abstract}
Summary
What is already known about this topic?

Attitudes of disapproval toward public health measures led to behaviors that could increase vulnerability to contracting coronavirus disease 2019 (COVID-19).

What is added by this report?

Chinese citizens rated the necessity of mitigation measures for combating COVID-19 higher than did Americans (4.81 vs. 4.03 on a $1-5$ scale). The China-US difference was attributable to 1) Chinese citizens having more confidence in scientists than Americans and 2) Chinese citizens almost invariably accepting the necessity of COVID-19 mitigation measures, regardless of their confidence in scientists.

What are the implications for public health practice?

Building public support for population health measures and public trust in science is crucial for handling epidemic crises.
\end{abstract}

Confirmed cases of coronavirus disease 2019 (COVID-19) have surpassed 175 million globally as of June 11, 2021. By then, the United States (US) has reported over 33 million infections, whereas China, the initial epicenter of the pandemic, has had 103,285 confirmed cases (1). Differences in the number of COVID-19 infections between China and the US might arise in part from different attitudes toward public health measures. Prior research suggested that Americans' support for public health measures varied with their trust in science (2). This study examined the China-US difference in attitudes toward COVID-19 mitigation measures and evaluated the role of belief in science in the China-US difference in the attitudes.

During March-July 2020, comparable surveys were conducted in China and the US. The survey found that Chinese respondents rated higher the necessity of mitigation measures for combating COVID-19 than did Americans. The China-US difference was attributable to the following: 1) Chinese citizens had higher confidence in scientists than Americans; and 2) Chinese citizens rated the necessity of COVID-19 mitigation measures more highly than Americans did, regardless of their confidence in scientists. The research findings suggest that building public support for population health measures and public trust in science is crucial for handling epidemic crises, especially in individualistic societies where citizen consent to public policy is key for policy effectiveness.

Attitudes of disapproval toward public health measures led to behaviors that could increase vulnerability to contracting COVID-19 (3). Nonpharmaceutical interventions such as lockdowns played an important role in containing COVID-19 in China (4). Both city-wide lockdowns (e.g., the lockdown of Wuhan) and residential-compound lockdowns (i.e., residents not being allowed to leave their residential compound without authorization) were implemented in China, with a high degree of compliance from Chinese people (5). In the US, stay-at-home orders were implemented across states, but individuals' behavioral responses varied greatly, with many Americans violating governmental directives (G).

The study conducted an online, opt-in survey of 9,014 Chinese adults in March-April 2020 and a follow-up survey with 5,403 (60\%) of the first survey respondents who participated in June-July 2020. Respondents from 31 provincial-level administrative divisions (PLADs) in the mainland of China were recruited by a professional survey firm through various online and offline channels. The research oversampled people living in Hubei Province; within each stratum (Hubei versus other PLADs), we further set quota based on gender, age, and education to ensure sample diversity. Because only the second survey asked about one of our key variables (confidence in scientists), our analytic sample in China drew on the 5,403 subjects who responded to both surveys.

In May 2020, an online survey of 2,523 adults in the US was conducted through Ipsos KnowledgePanel, 
a probability-based Internet panel representative of US adults. Based on the US Postal Service's Delivery Sequence File, the sample was selected using a disproportionate stratified sampling methodology. After excluding 33 observations (1.3\%) with missing data on the variables used in this study, our final analytic US sample consisted of 2,490 respondents. The samples were weighted according to gender, age, and education, so that China and US sample distributions matched along these three dimensions with the 2015 Chinese $1 \%$ Sample Census and the 2015 American Community Survey, respectively. Although we oversampled Hubei residents in China, region was not included as a weighing variable because additional analysis indicated that PLADs did not significantly explain variation in attitudes toward COVID-19.

The reseach measured respondents' attitudes toward COVID-19 using a 1-5 scale of the necessity of mitigation measures for combating COVID-19 (1=not necessary at all; 5=very necessary). Given that there were different policies implemented in the two countries, US respondents assessed the necessity of stay-at-home orders, whereas Chinese respondents were asked to rate the necessity of city-wide lockdowns and of residential-compound lockdowns. In the Chinese sample, we constructed a composite scale by calculating the average score across the two items (Cronbach's alpha $=0.69$ ). Belief in science was measured through a question adopted from a Pew Research Center survey ( 7 ): "How much confidence, if any, do you have in scientists to act in the best interest of the public?" (No confidence at all, not too much

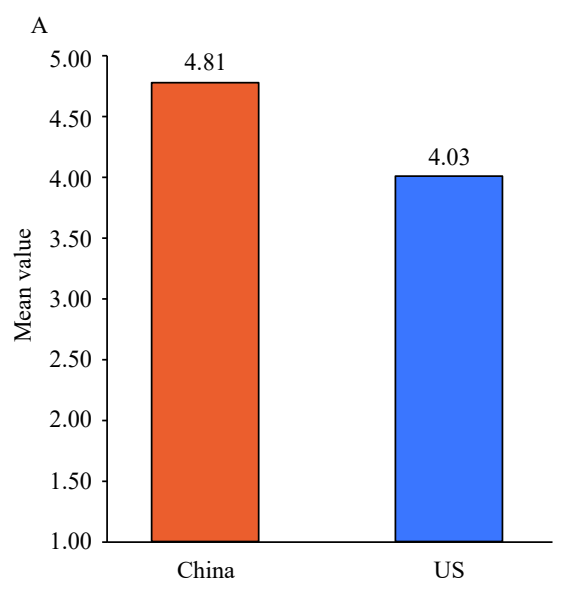

confidence, a fair amount of confidence, a great deal of confidence).

The study applied a standard demographic standardization technique (8). The overall mean value of attitudes toward COVID-19 was calculated as follows:

$$
M_{\text {ean }} \text { attitudes toward COVID-19 }=\sum_{k=1}^{4} P_{k} \times m_{k},
$$

where $P_{k}$ denoted the proportion of the $k$ th category of belief in science and $m_{k}$ denoted the mean level of attitudes toward COVID-19 for the $k$ th category of belief in science. We created counterfactual means of US attitudes toward COVID-19 in two ways: applying to the US either 1) China's distribution of belief in science $\left(P_{k}\right)$ or 2) China's attitudes toward COVID-19 by belief in science $\left(m_{k}\right)$. Stata (version 16.1; College Station, TX: StataCorp) was used to conduct all analyses.

On average, Chinese respondents rated the necessity of COVID-19 mitigation measures at a significantly higher level than US respondents (Panel A of Figure 1: 4.81 vs. 4.03). In addition, Chinese adults had greater confidence in scientists than did American adults (Panel B of Figure 1). For example, 50\% of Chinese and $33 \%$ of Americans had a great deal of confidence in scientists. In contrast, $17 \%$ of Americans did not have much confidence in scientists and $5 \%$ had no confidence at all, compared to only $7 \%$ and $1 \%$ in China, respectively.

In terms of attitudes toward COVID-19 by belief in science (Figure 2), Chinese respondents without confidence in scientists gave lower ratings to the necessity of COVID-19 mitigation measures (4.17),
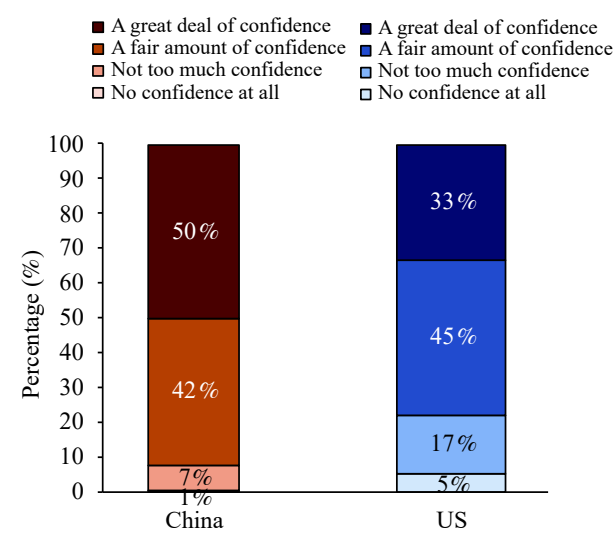

FIGURE 1. Mean of attitudes toward COVID-19 and percentage distribution of belief in science, by country, 2020.

(A) Mean of attitudes toward COVID-19 mitigation measures. (B) Percentage distribution of confidence in scientists. 
but all other Chinese respondents rated the necessity very high (4.77-4.83). By contrast, there was a clearer relationship among American respondents, such that greater confidence in scientists was strongly and positively associated with support for mitigation measures. The average scores rating the necessity of COVID-19 mitigation measures (in parentheses) corresponded to confidence in scientists as follows: no confidence at all in scientists (2.79), not too much confidence (3.24), a fair amount of confidence (4.02), and a great deal of confidence (4.65).

The results of demographic standardization were

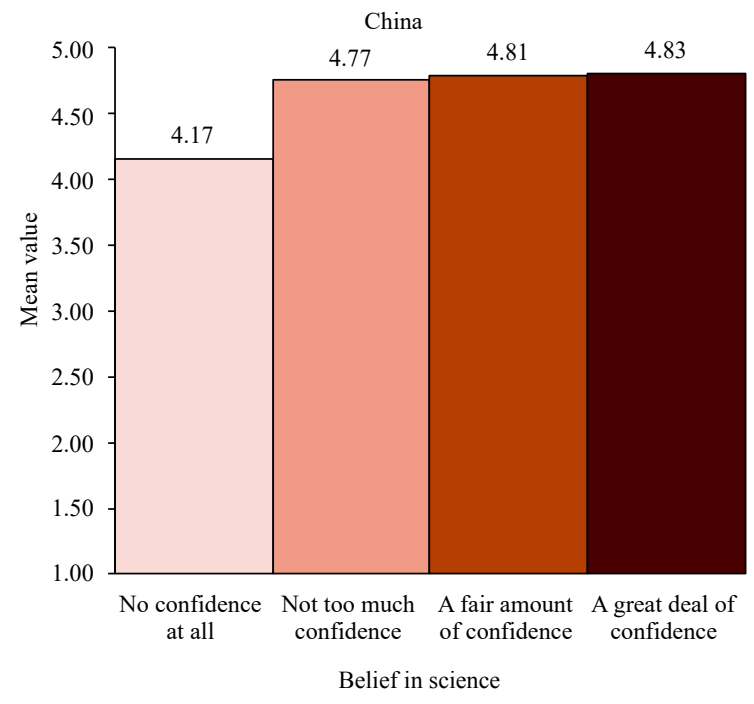

shown in Figure 3. The observed means indicated Chinese respondents' higher average rating of the necessity of mitigation measures when compared to Americans (4.81 vs. 4.03), with a difference of 0.78 . When China's distribution of belief in science $\left(P_{k}\right)$ was applied to that of the US and Americans' attitudes toward COVID-19 by belief in science $\left(m_{k}\right)$ was kept as observed, the counterfactual mean for the US was 4.27, resulting in a China-US difference of 0.54 , a $30 \%$ reduction from the observed gap. When China's $m_{k}$ was applied to the US and America's $P_{k}$ was kept as observed, the counterfactual mean for the US

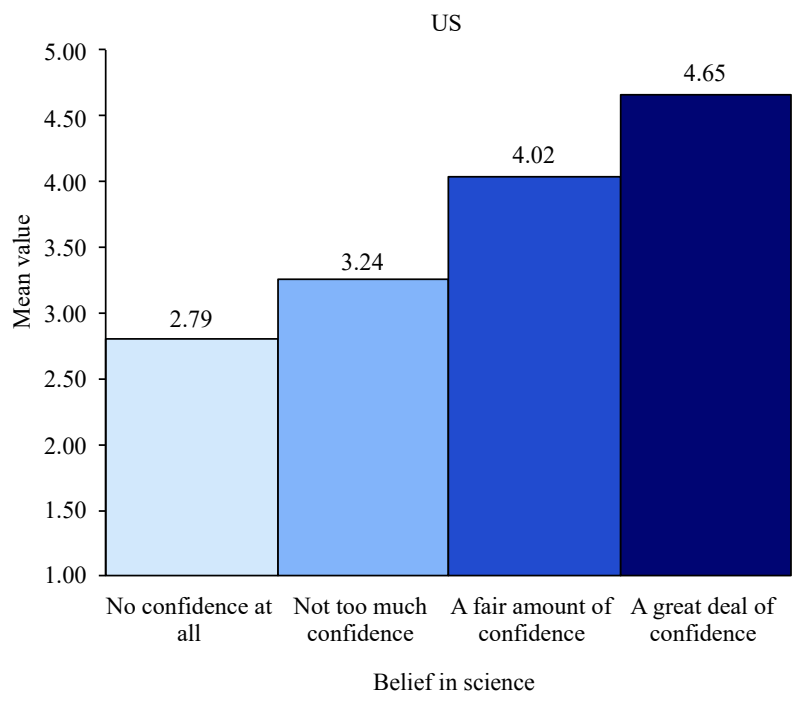

FIGURE 2. Mean of attitudes toward COVID-19, by belief in science and country, 2020.

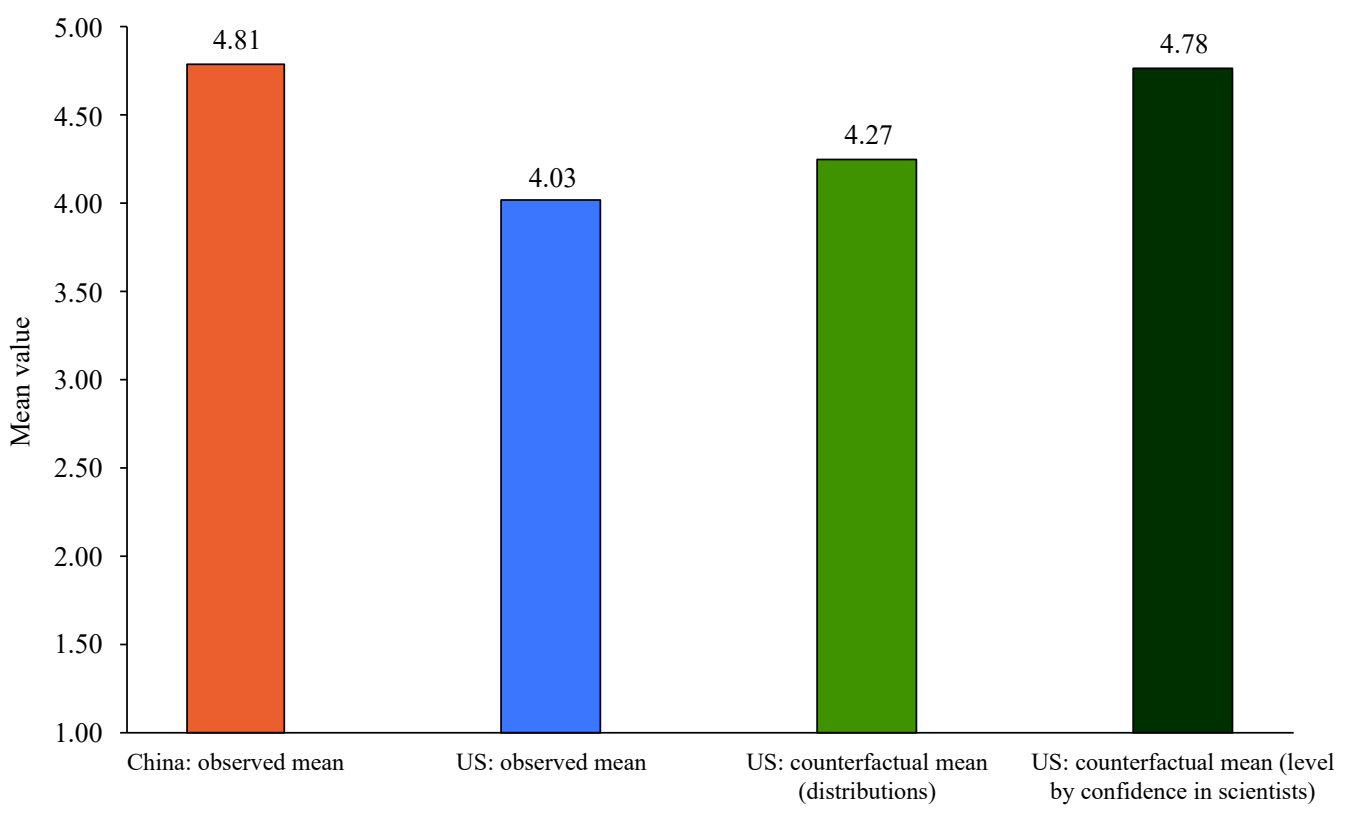

FIGURE 3. Observed and counterfactual mean values of attitudes toward COVID-19, 2020. 
was 4.78, reducing the China-US difference to practically nil (only 0.03). That is, if Americans held the same attitudes as Chinese for each category of confidence in scientists, the China-US difference in attitudes toward COVID-19 would have been almost entirely explained.

\section{DISCUSSION}

This study drew on original survey data from China and the US to compare attitudes toward COVID-19 and their associations with belief in science in the two countries. This reseach measured attitudes toward COVID-19 with survey questions about the necessity of mitigation measures (lockdowns or stay-at-home orders) for combating COVID-19. This research assessed belief in science through respondents' level of confidence in scientists to act in the public interest. We showed that Chinese respondents rated higher the necessity of mitigation measures for combating COVID-19 than did American respondents. The China-US difference could be decomposed into two components: (1) Chinese people had higher confidence in scientists than did Americans, and (2) Chinese rated the necessity of COVID-19 mitigation measures more highly than Americans did, regardless of level of confidence in scientists.

The US is unique among Western developed nations in having a large portion of its citizenry who does not trust science (9). Previous research showed that over $30 \%$ of Americans thought that evolution was "absolutely false," compared to 7\%-15\% in European countries (9). Distrust in science may diminish individuals' confidence in scientists and government policies recommended by scientists. Chinese people, however, largely trust scientists, and over $90 \%$ of the Chinese public regarded scientists as role models (10). We demonstrated that belief in science played a role in accounting for the China-US difference in attitudes toward COVID-19.

This study was subject to some limitations. Although our China and US data were collected during similar time periods, the two countries were at different stages of the pandemic: the COVID-19 outbreak was under control in China, whereas in the US, daily new cases were rising. Given the crosssectional survey design, we were unable to establish causality or capture changes over time in individuals' attitudes toward COVID-19 and belief in science. Additionally, as we lacked data on individuals'
COVID-19 infection histories, we cannot ascertain the potential impact of COVID-19-related experiences on attitudes toward COVID-19. Finally, it was possible that confidence in scientists was associated with trust in other authorities such as the government, which in turn was related to support for and conformity with the government's COVID-19 mitigation measures (2). However, we did not have data to test this alternative explanation.

In conclusion, Chinese people's overall confidence in scientists and invariably high levels of support for COVID-19 mitigation policies have allowed China to contain COVID-19 with strong government interventions that were well supported by the public. By contrast, a large number of Americans' distrust in scientists may have undermined their acceptance of science-based government policies (2). Individuals' approving attitudes toward public health measures have been shown to promote adoption of behaviors that help reduce infection risk and slow COVID-19 transmission (3). Thus, the China-US difference in the severity of the COVID-19 outbreak may be partly attributable to differences in attitudes towards COVID-19 mitigation measures between China and the US. Taken together, our findings underscore that public trust in science and public support for population health measures are crucial for controlling the spread of COVID-19, especially in individualistic societies where citizen consent to public policy strongly influences policy effectiveness.

Funding: The Canadian Institutes of Health Research (OV7-170372); Fundamental Research Funds for the Central Universities, the Research Funds of Renmin University of China; the financial support for data collection from Princeton University.

doi: $10.46234 / \mathrm{ccdcw} 2021.157$

\# Corresponding author: Yongai Jin, jinyongai0416@ruc.edu.cn.

1 Department of Sociology, University of British Columbia, Vancouver, Canada; ${ }^{2}$ Center for Population and Development Studies, Renmin University of China, Beijing, China; ${ }^{3}$ Department of Sociology, Princeton University, New Jersey, USA; ${ }^{4}$ Center for Social Research, Peking University, Beijing, China.

Submitted: June 18, 2021; Accepted: June 26, 2021

\section{REFERENCES}

1. Johns Hopkins Coronavirus Resource Center. 2020. https:// coronavirus.jhu.edu/map.html. [2021-6-11].

2. Barry C, Han H, Mcginty B. Trust in science and COVID-19. 2020. https://www.jhsph.edu/covid-19/articles/trust-in-science-and-covid19.html.[2021-5-26]. 
3. Galasso V, Pons V, Profeta P, Becher M, Brouard S, Foucault M. Gender differences in COVID-19 attitudes and behavior: panel evidence from eight countries. Proc Natl Acad Sci USA 2020; 117(44):27285 - 91. http://dx.doi.org/10.1073/pnas.2012520117.

4. Lai SJ, Ruktanonchai NW, Zhou LC, Prosper O, Luo W, Floyd JR, et al. Effect of non-pharmaceutical interventions to contain COVID-19 in China. Nature 2020;585(7825):410 - 3. http://dx.doi.org/10.1038/ s41586-020-2293-x.

5. Qian Y, Hanser A. How did Wuhan residents cope with a 76-day lockdown? Chin Sociol Rev 2021;53(1):55 - 86. http://dx.doi.org/ 10.1080/21620555.2020.1820319.

6. Weill JA, Stigler M, Deschenes O, Springborn MR. Social distancing responses to COVID-19 emergency declarations strongly differentiated by income. Proc Natl Acad Sci USA 2020;117(33):19658 - 60. http://dx.doi.org/10.1073/pnas.2009412117

7. Funk C, Hefferon M, Kennedy B, Johnson C. Trust and mistrust in Americans' views of scientific experts. 2019. https://www.pewresearch. org/science/2019/08/02/trust-and-mistrust-in-americans-views-ofscientific-experts/. [2021-5-26].

8. Preston S, Heuveline P, Guillot M. Demography: measuring and modeling population processes. Malden, MA: Blackwell Publishers. 2000. http://book.kongfz.com/255562/2252100268/.

9. Miller JD, Scott EC, Okamoto S. Public acceptance of evolution. Science 2006;313(5788):765 - 6. http://dx.doi.org/10.1126/science. 1126746.

10. Li J. Chinese "trust scientists more than government". 2011. https:// www.scidev.net/global/news/chinese-trust-scientists-more-than-gover nment/. [2021-5-26]. 